\title{
Development of a Thermal Transport Database for Air Plasma Sprayed $\mathrm{ZrO}_{2}-\mathrm{Y}_{2} \mathrm{O}_{3}$ Thermal Barrier Coatings
}

\author{
Hsin Wang, Ralph B. Dinwiddie, and Wallace D. Porter
}

(Submitted August 10, 2009; in revised form January 11, 2010)

\begin{abstract}
Thermal diffusivities of air plasma sprayed (APS) thermal barrier coatings (TBCs) were measured by the laser flash method. The data were used to calculate thermal conductivity of TBCs when provided with density and specific heat data. Due to the complicated microstructure and other processing-related parameters, thermal diffusivity of TBCs can vary as much as three- to four-fold. Data collected from over 200 free-standing $\mathrm{ZrO}_{2}-7-8 \mathrm{wt} . \% \mathrm{Y}_{2} \mathrm{O}_{3}$ TBCs are presented. The large database gives a clear picture of the expected "band" of thermal diffusivity values. When this band is used as a reference for thermal diffusivity of a specific TBC, the thermal transport property of the TBC can be more precisely described. This database is intended to serve researchers and manufacturers of TBCs as a valuable resource for the evaluation of TBCs.
\end{abstract}

Keywords laser flash, plasma spray, TBC, thermal diffusivity, $\mathrm{ZrO}_{2}$

\section{Introduction}

Thermal conductivity is one of the most important properties of thermally sprayed thermal barrier coatings (TBCs) (Ref 1-3). Serving as a thermal protective layer for alloy-based engine components, TBCs can increase component reliability and increase the operating temperature resulting in higher efficiency and better environmental benefits. One of the major issues concerning the thermal conductivity of TBCs is that there are no standard values even for the most widely used composition of $\mathrm{ZrO}_{2}$ 7-8wt. $\% \mathrm{Y}_{2} \mathrm{O}_{3}$ (YSZ). In this study, as-sprayed YSZ can have thermal conductivity values as low as 0.50 to $1.0 \mathrm{~W} / \mathrm{m} \mathrm{K}$. After heat treatment near the application temperature, thermal conductivity of the same TBC can increase to as high as $2.0 \mathrm{~W} / \mathrm{m} \mathrm{K}$. The wide spread of values makes the correct assessment of the thermal transport property and prediction of engine component temperature difficult.

Over the years, many research groups have studied thermal conductivity of TBCs (Ref 4-20). When the study concentrated on thermal transport properties, a group of 5-15 samples were usually prepared. When the focus was on other properties, thermal conductivity was usually measured on just 1-2 specimens as a reference value for the TBC. It is also common for companies to conduct

Hsin Wang, Ralph B. Dinwiddie, and Wallace D. Porter, Oak Ridge National Laboratory, Oak Ridge, TN 37831-6064. Contact e-mail:wangh2@ornl.gov. substantial proprietary studies to select and evaluate their TBCs. However, these studies produce incomplete pictures of thermal transport properties and are limited by the number of specimens tested.

This paper reports the development of a thermal transport property database of TBCs built upon over 200 specimens from industries and various research groups. The data were collected over the past 12 years as part of a Department of Energy (DOE) High Temperature Materials Laboratory user program. The database is based on TBCs with the basic composition of 7-8 wt.\% YSZ. In a few cases, small amounts of impurities were present due to processing conditions. The impurity levels were insignificant to cause theoretical density or detectable specific heat changes. In most cases, processing parameters and postspray heat treatments were varied resulting in different microstructures.

The database is presented in the form of thermal diffusivity because it was directly measured by the laser flash method (Ref 21, 22). To obtain thermal conductivity, $k$, one simply needs to multiply diffusivity, $\alpha$, density, $\rho$, and specific heat, $C_{\mathrm{p}}$ :

$k=\alpha \rho C_{\mathrm{p}}$

The densities of TBCs (at times, measured on the same coating at elevated temperatures) varied and were not provided for each specimen. The specific heat of a group of samples was usually measured on one specimen when the composition of the TBCs remained the same and the only difference was in microstructures. This is because $C_{\mathrm{p}}$ is known to only change with composition and is not dependent on microstructure. Therefore, these two parameters are usually known and do not have the same variations as thermal diffusivity. This thermal diffusivity database can be used to compare TBCs with spraying parameters and post-spray heat treatments. The purpose is 
to provide the TBC researchers and industry a comprehensive picture of thermal transport properties of the YSZ used in TBCs. In the meantime, the database can serve as benchmark information for new TBC research and development.

\section{Experimental}

Thermal diffusivities of TBCs were measured using the Anter thermal diffusivity system (Ref 23). The measurements followed ASTM Standard E1641 (Ref 21). Some room temperature thermal diffusivity was measured using the xenon flash system developed at the Oak Ridge National Laboratory (ORNL) (Ref 24). The tests were conducted over 12 years in collaboration with 16 institutes and companies as well as research sponsored by the DOE.

Figure 1 shows the picture of the Anter FL5000 laser flash system with a six-sample carousel. A Nd-glass laser was used to deliver a short heating pulse to the sample surface. The standard geometry for all TBC samples was $12.5 \mathrm{~mm}$ in diameter and $0.2-1.0 \mathrm{~mm}$ thick. Free-standing TBCs were obtained by chemically etching the substrate and bond coat or spraying directly onto graphite and stripping the coating. The TBCs were coated with a thin layer of a metallic film or 4-5 coats of a sub-micrometer colloidal graphite spray to prevent light penetration from the front surface and limit the back surface temperature detection to only the surface. Up to six samples can be loaded for each test. The low temperature, i.e. room temperature to $550{ }^{\circ} \mathrm{C}$, tests were conducted in an aluminum furnace with an InSb infrared detector. The high-temperature tests, i.e. from 600 to $1400{ }^{\circ} \mathrm{C}$, were conducted in a graphite furnace with a silicon detector. In order to ensure the minimum temperature rise, laser

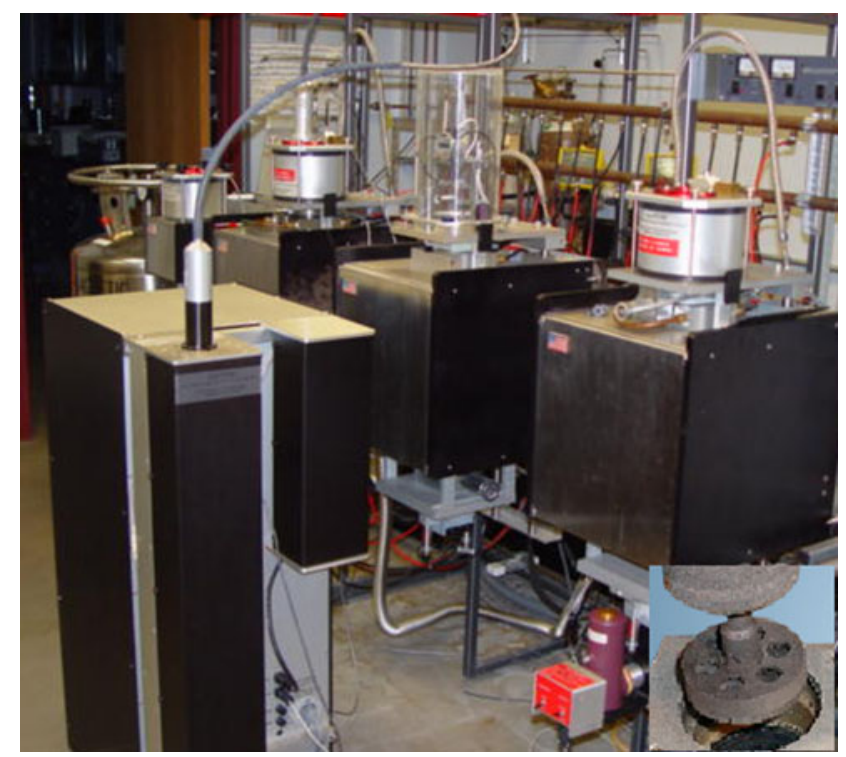

Fig. 1 Laser flash diffusivity system, Anter FL5000 with a 6-sample carousel power was limited so that the back surface temperature rise was maintained below $5{ }^{\circ} \mathrm{C}$. The detector voltage (instead of the temperature) was recorded at high speed. As long as the temperature versus detector voltage relationship is linear, there is no need to convert the voltage output into temperature. Since only sample thickness and half rise time, i.e. time for the back surface temperature to reach half of the maximum value, are used in the thermal diffusivity calculation, the system is actually making a time domain measurement which will be much more accurate than a temperature measurement. All the high-temperature tests were conducted in a nitrogen environment. The normal temperature intervals were $100{ }^{\circ} \mathrm{C}$.

Specific heat, $C_{\mathrm{p}}$, of more than ten TBC samples was measured using a differential scanning calorimeter (DSC), Netszctch 404C. The specific heat is obtained by comparing heat flows of the sample calibrated with baseline and sapphire standard measurements as outlined in ASTM E1269. A Debye-based model or empirical curve fitting can be used to describe the $C_{\mathrm{p}}$ versus temperature curve to get accurate temperature dependence.

The density of the specimen was treated as a constant. Room temperature values were obtained by measuring the weight and apparent volume of the specimens. The volume change at elevated temperature due to thermal expansion resulted in a much smaller error than the typical experimental error of $6-7 \%$ of thermal conductivity measurements.

\section{Results and Discussion}

Thermal diffusivity versus temperature data of more than 133 TBCs are shown in Fig. 2. This plot disregards identities of all samples and only treats them as air plasma sprayed (APS) TBCs with the same compositions. In order to emphasize the spread of thermal diffusivity at each temperature, the values are plotted using the same symbols and the temperature dependence of each sample was not shown by linking the data points. The general trend gives more than 3.7-fold change near room temperature and about three-fold change at the high-temperature end.

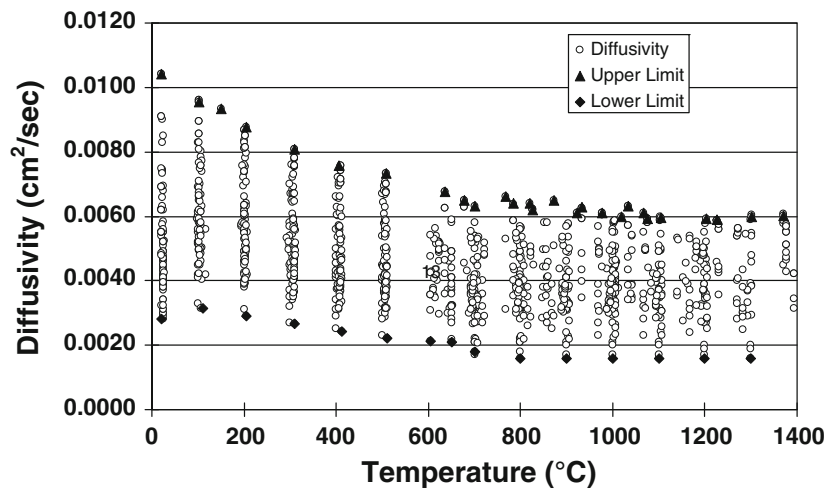

Fig. 2 Thermal diffusivity of 133 7-8 YSZ TBCs forms a "band". The upper and lower limits are marked with solid symbols 
It should be noted that factors such as density, porosity, and microstructure can strongly affect the thermal diffusivity of TBCs. While including these parameters will be an ideal study, this paper does not intend to present detailed property-processing parameters-microstructure correlation of the TBCs. This is mainly because the types of data presented in this study were a collection of many subsets over 12 years. A number of studies using data subsets (Ref 5, 6, 9, 11-14) focused on the effects of microstructure, porosity, and other factors. Special focus of this study is placed on thermal diffusivity rather than thermal conductivity in which density/porosity of the TBCs would introduce a variable that could make data analysis more complicated.

Using Fig. 2, boundaries can be drawn illustrating the upper and lower limit of expected thermal diffusivity values as shown in Fig. 3. The upper boundary curve can be expressed by a second-order polynomial equation:

$\alpha=3 \times 10^{-9} T^{2}-8 \times 10^{-6} T+0.0103\left(\mathrm{~cm}^{2} / \mathrm{s}\right)$

and the low boundary curve can be expressed as:

$\alpha=9 \times 10^{-10} T^{2}-2 \times 20^{-6} T+0.0032\left(\mathrm{~cm}^{2} / \mathrm{s}\right)$

In both Eq 2 and 3, $T$ is in ${ }^{\circ} \mathrm{C}$. It should be noted that it is still possible for a particular TBC to have diffusivity values outside the boundary due to processing conditions and microstructures not covered in these studies. This database comes from a collection of TBCs from multiple sources which are considered to be the "best available" materials over this 12-year study. In fact, if an as-sprayed TBC exhibits thermal diffusivity values lower than the boundary and does not increase very much towards the upper boundary upon heating, it could be an indication of significant improvement of the material. Equation 2, i.e. the upper boundary, is regarded as representing the more stable values for YSZ TBCs. From the specimens used in the studies, coatings at the lower boundary were usually not stable at high temperatures. TBCs having diffusivity close to the lower limits were usually high in porosity and have thermally unstable microstructures. For example, the aging effect (increase in thermal diffusivity due to sintering) can cause an irreversible change in thermal diffusivity and is also known as the hysteresis effect (Ref 14).

For a quick assessment of the thermal transport properties of a TBC, one can test an as-sprayed specimen and a specimen that has been heat-treated in air for $500 \mathrm{~h}$ or more. The thermal diffusivity curves of such two TBC specimens can be plotted with the two boundary curves for YSZ in Fig. 3. The heat-treated sample curve should give the indication of the in-service thermal transport properties of the TBC. The change in thermal diffusivity is usually accompanied by a change in microstructure. The aging effect is caused by densification of the coatings. Recent development at SUNY Stony Brook resulted in extended knowledge of microstructure or microstructure control (Ref 25,26$)$ in these coating systems. Combining the understanding of microstructure with the thermal transport properties could provide a powerful tool for TBC development.

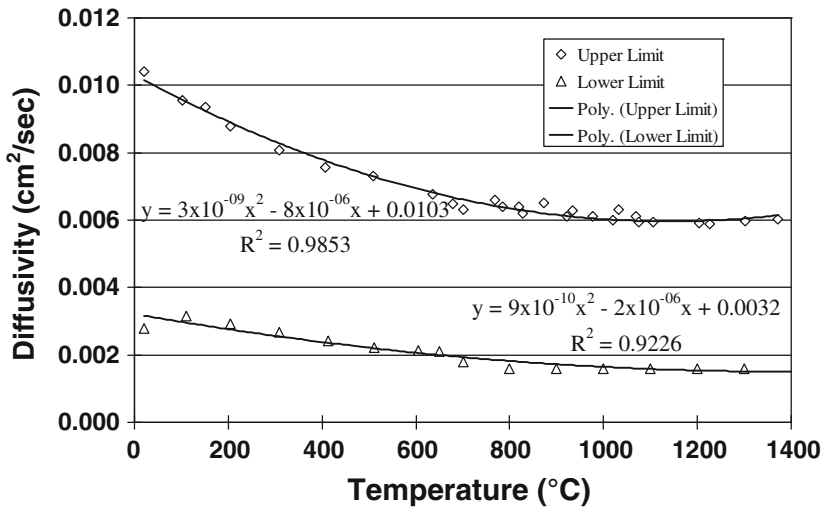

Fig. 3 Upper and lower limits of diffusivity can be used to evaluate TBC performance

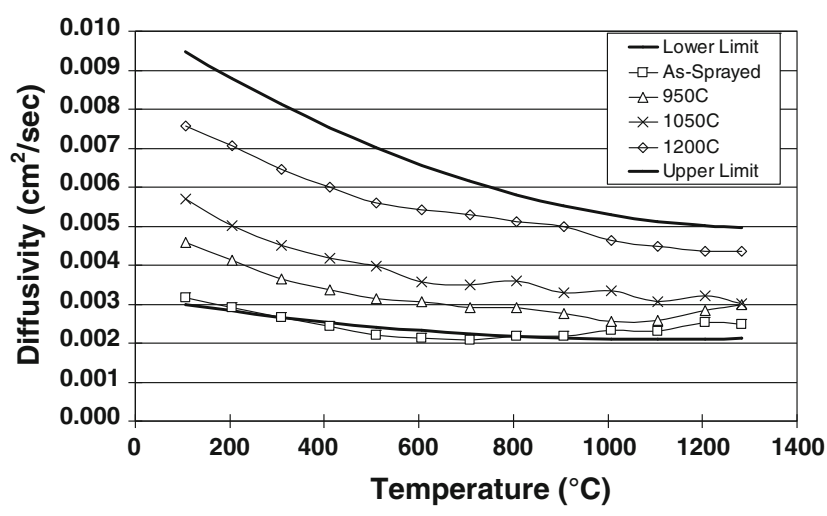

Fig. 4 Study of heat treatment of 7-8 YSZ

If a specific TBC is to be studied, the thermal diffusivity can be plotted with the YSZ data boundaries as background. In Fig. 4, a heat treatment study was conducted with as-sprayed coating and coatings that underwent heat treatments at $950{ }^{\circ} \mathrm{C}(500 \mathrm{~h}), 1050{ }^{\circ} \mathrm{C}(500 \mathrm{~h})$, and $1200{ }^{\circ} \mathrm{C}(2000 \mathrm{~h})$. With the help of the database, the effect of aging can be tracked very closely. It was noted the final thermal diffusivity (after $1200{ }^{\circ} \mathrm{C}$ annealing) moved toward the upper limit of the database boundary. The database boundaries, as shown in Fig. 4, become important to evaluate the thermal transport property of a specific TBC. It is the final design temperature of the TBC application that determines the maximum heat treatment temperature below which the thermal diffusivity values are stable.

This database can also be used to assist the development of other new TBCs prepared by the APS process. Small variations in the impurity levels and microstructure variations via starting powder morphology, spray conditions, and heat treatment will usually fall within the database boundaries. Changes in composition and crystal structure may result in a larger shift of thermal diffusivity. However, the APS processing of non-7-8 YSZ TBC compositions may produce similar microstructures and the new TBCs showed the same aging behavior. Using the 7-8 


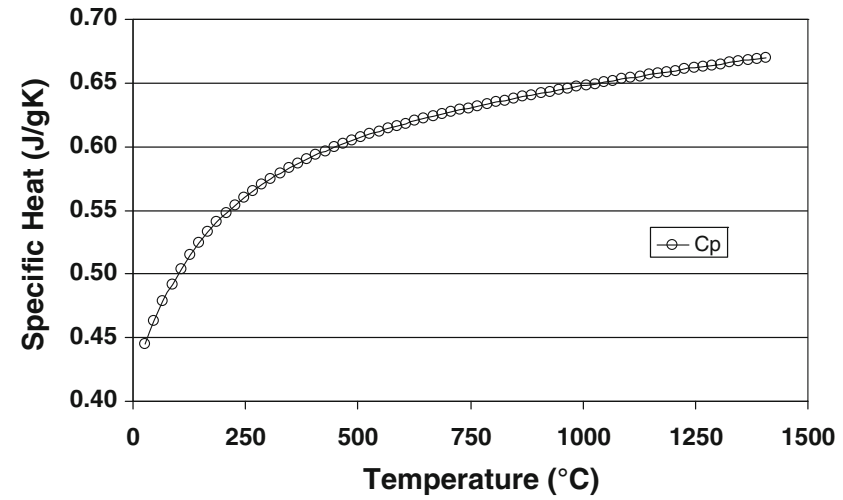

Fig. 5 Specific heat of 7-8 YSZ measured by DSC

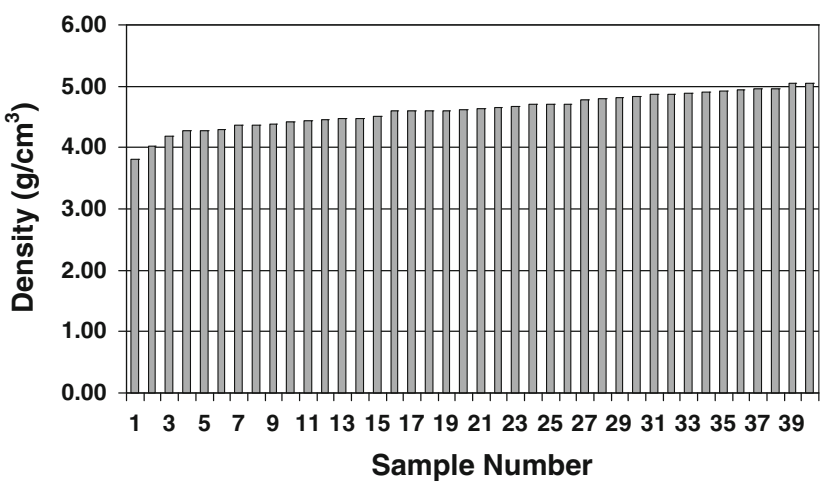

Fig. 6 Density distribution of a group of 40 as-sprayed TBCs

YSZ boundaries as a reference can aid the new TBC development.

Thermal conductivity is often a design parameter for TBCs applications. The thermal conductivity of a TBC can be calculated by Eq 1. The specific heat of 7 sets of TBCs is used to generate the curve shown in Fig. 5. A general curve-fitting equation is used:

$C_{\mathrm{p}}=m_{1}+m_{2} T+m_{3} T^{-0.5}+m_{4} T^{-2}+m_{5} T^{-3}$

where $m_{1}=0.60045, m_{2}=4.296 \mathrm{E}-5, m_{3}=0.22845, m_{4}=$ $-24201, m_{5}=2.3668 \mathrm{E}-6$ and $T$ is temperature in Kelvin. This $C_{\mathrm{p}}$ curve is the same for all YSZ TBCs and it does not change with microstructure variations.

Figure 6 shows the distribution of density of $40 \mathrm{YSZ}$ TBCs. The density values range from 3.80 to $5.05 \mathrm{~g} / \mathrm{cm}^{3}$. The average value is $4.16 \mathrm{~g} / \mathrm{cm}^{3}$. Since the density of each sample, especially the as-sprayed TBC, can vary after the heat treatment, the calculated thermal conductivity in Fig. 7 is just a demonstration of the range of the property assuming all the coatings have the same average density. In order to have more meaningful data analysis, the thermal diffusivity database should be used since they are directly measured values. The accuracy of thermal conductivity of the TBCs depends on the knowledge of density variations as a function of temperature and time. Using the estimated density, thermal conductivity of most

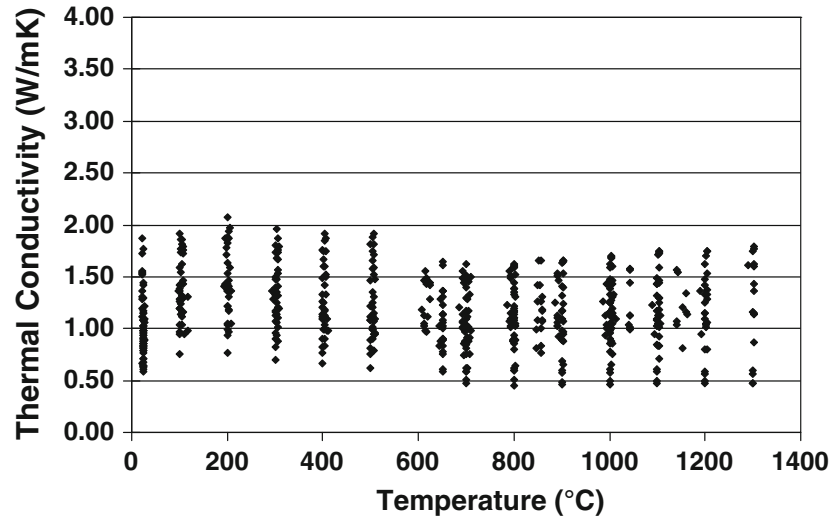

Fig. 7 Thermal conductivity of most YSZ TBCs used in this study

7-8 YSZ TBCs ranged from 0.50 to $2.00 \mathrm{~W} / \mathrm{m} \mathrm{K}$ over the entire temperature range.

\section{Conclusions}

A thermal diffusivity based database has been established for thermally sprayed 7-8 YSZ TBCs. Thermal diffusivity upper and lower boundaries as a function of temperature were identified. These boundaries are used to evaluate transport properties of TBCs. Using specific heat data obtained from DSC measurements, thermal conductivity values of 7-8 YSZ were found to be within 0.5$2.0 \mathrm{~W} / \mathrm{m} \mathrm{K}$ from room temperature to $1200{ }^{\circ} \mathrm{C}$. This database is not only a useful tool for transport study of 7-8 YSZ TBCs, it is also a valuable baseline for new TBC development.

\section{Acknowledgments}

The authors would like to thank all the HTML users in the past 12 years for allowing this database to be developed. Users contributed to the thermal diffusivity database include GE Aircraft Engine, GE CR\&D, Northwestern University, Siemens Westinghouse, Solar Turbine, Purdue University, University of Central Florida, Pennsylvania State University, and State University of New York at Stony Brook. This work has been sponsored by the Assistant Secretary for Energy Efficiency and Renewable Energy, Office of Vehicle Technologies, as part of the High Temperature Materials Laboratory User Program at Oak Ridge National Laboratory by the UT-Battelle LLC, for the Department of Energy under contract DE-AC05000OR22725.

\section{References}

1. R.A. Miller, Current Status of Thermal Barrier Coatings, Surf. Coat. Technol., 1987, 30(1), p 1-11 
2. R.A. Miller, Thermal Barrier Coatings for Aircraft Engines: History and Directions, J. Therm. Spray Technol., 1997, 6(1), p 35-42

3. R. Taylor, J.R. Brandon, and P. Morrell, Microstructure, Composition and Property Relationships of Plasma-Sprayed Thermal Barrier Coatings, Surf. Coat. Technol., 1992, 50(2), p 141-149

4. R. Dutton et al., Effect of Heat Treatment on the Thermal Conductivity of Plasma-Sprayed Thermal Barrier Coatings, J. Therm. Spray Technol., 2000, 9(2), p 204-209

5. B. Ercan, K.J. Bowman, R.W. Trice, H. Wang, and W.D. Porter, Effect of Initial Powder Morphology on Thermal and Mechanical Properties of Stand-Alone Plasma-Sprayed $7 \mathrm{wt} \% \quad \mathrm{Y}_{2} \mathrm{O}_{3}-\mathrm{ZrO}_{2}$ Coatings, Mater. Sci. Eng. A, 2006, 435, p 212-220

6. S. Raghavan, H. Wang, R.B. Dinwiddie, W.D. Porter, R. Vassen, D. Stover, and M.J. Mayo, $\mathrm{Ta}_{2} \mathrm{O}_{5} / \mathrm{Nb}_{2} \mathrm{O}_{5}$ and $\mathrm{Y}_{2} \mathrm{O}_{3}$ Co-doped Zirconias for Thermal Barrier Coatings, J. Am. Ceram. Soc., 2004, 87(3), p 431-437

7. H. Wang and R.B. Dinwiddie, Characterization of Thermal Barrier Coatings Using Thermal Methods, Adv. Eng. Mater., 2001, 3(7), p 465-468

8. Y.J. Su, H. Wang, W.D. Porter, A.R. de Arellano Lopez, and K.T. Faber, Thermal Conductivity and Phase Evolution of Plasma-Sprayed Multilayer Coatings, J. Mater. Sci., 2001, 36(14), p 3511-3518

9. R.W. Trice et al., Effect of Heat Treatment on Phase Stability, Microstructure, and Thermal Conductivity of Plasma-Sprayed YSZ, J. Mater. Sci., 2002, 37(11), p 2359-2365

10. Y.J. Su, R.W. Trice, K.T. Faber, H. Wang, and W.D. Porter, Thermal Conductivity, Phase Stability, and Oxidation Resistance of $\mathrm{Y}_{3} \mathrm{~A}_{15} \mathrm{O}_{12}(\mathrm{YAG}) / \mathrm{Y}_{2} \mathrm{O}_{3}-\mathrm{ZrO}_{2}$ (YSZ) Thermal-Barrier Coatings, Oxid. Met., 2004, 61(3-4), p 253-271

11. S. Raghavan, H. Wang, W.D. Porter, R.B. Dinwiddie, and M. Mayo, Thermal Properties of Zirconia Co-doped with Trivalent and Pentavalent Oxides, Acta Mater., 2001, 49, p 169-179

12. S. Raghavan, H. Wang, R.B. Dinwiddie, W.D. Porter, and M. Mayo, The Effect of Grain Size, Porosity and Yttria Content on the Thermal Conductivity of Nanocrystalline Zirconia, Scr. Mater., 1998, 39(8), p 1119-1125

13. A. Mogro-Campero, C.A. Johnson, P.J. Bendarczyk, R.B. Dinwiddie, H. Wang, Effect of Gas Pressure on Thermal Conductivity of Zirconia Thermal Barrier Coating, Surf. Coat. Technol., 1997, 94-95, p 102-105

14. H.E. Eaton, J.R. Linsey, and R.B. Dinwiddie, The Effect of Thermal Aging on the Thermal Conductivity of Plasma Sprayed
Fully Stabilized Zirconia, Thermal Conductivity 22, T. Tong, Ed., Technomic Publications, 1994, p 289-300

15. Y. Tan, A. Sharma, J. P. Longtin, S. Sampath, and H. Wang, Image-Based Modeling for Assessing Thermal Conductivity of Thermal Spray Coatings at Ambient and High Temperature, IMECE2006-15972, 2006

16. F. Cernuschi, P. Bianchi, M. Leoni, and P. Scardi, Thermal Diffusivity/Microstructure Relationship in Y-PSZ Thermal Barrier Coatings, J. Therm. Spray Technol., 1999, 8(1), p 102-109

17. D. Zhu and R.A. Miller, Thermal Conductivity and Elastic Modulus Evolution of Thermal Barrier Coatings Under High Heat Flux Conditions, J. Therm. Spray Technol., 2000, 9(2), p 175-180

18. I. Sevostianov and M. Kachanov, Anisotropic Thermal Conductivities of Plasma-Sprayed Thermal Barrier Coatings in Relation to the Microstructure, J. Therm. Spray Technol., 2000, 9(4), p 478482

19. A. Cipitria, I.O. Golosnoy, and T.W. Clyne, A Sintering Model for Plasma-Sprayed Zirconia TBCs. Part I: Free-standing Coatings, Acta Mater., 2009, 57(4), p 980-992

20. I.O. Golosnoy, S.A. Tsipas, and T.W. Clyne, An Analytical Model for Simulation of Heat Flow in Plasma-Sprayed Thermal Barrier Coatings, J. Therm. Spray Technol., 2005, 14(2), p 205-214

21. ASTM, E 1461-01 Standard Test Method for Thermal Diffusivity of Solids by the Flash Method, ASTM International

22. W.J. Parker et al., Flash Method of Determining Thermal Diffusivity, Heat Capacity, Thermal Conductivity, J. Appl. Phys., 1961, 32(9), p 1679

23. H. Wang, R.B. Dinwiddie, and P.A. Gaal, Multiple Station Thermal Diffusivity Instrument, Thermal Conductivity 23, K.E. Wilkes, R.B. Dinwiddie, and R.S. Graves, Ed., 1996, p 119-127

24. H. Wang and R.B. Dinwiddie, Development of a Labview ${ }^{\mathrm{TM}}$ Based Portable Thermal Diffusivity System, Thermal Conductivity 27, H. Wang and W.D. Porter, Ed., Destech Publishing Co., 2004, p 284-292

25. A. Kulkarni, Z. Wang, T. Nakamura, S. Sampath, A. Goland, H. Herman, J. Allen, J. Ilavsky, G. Long, J. Frahm, and R.W. Steinbrech, Comprehensive Microstructural Characterization and Predictive Property Modeling of Plasma Sprayed Zirconia Coatings, Acta Mater., 2003, 51(9), p 2457-2475

26. A. Kulkarni, A. Vaidya, A. Goland, S. Sampath, and H. Herman, Processing Effects on Porosity-Property Correlations in Plasma Sprayed Yttria Stabilized Zirconia Coatings, Mater. Sci. Eng. A, 2003, 359, p 100-111 